\title{
2009 ADSA-ASAS Sectional Awards
}

\section{Northeast ADSA-ASAS Distinguished Service Award}

Robert H. Miller, who retired from USDA's Agricultural Research Service (ARS) in 1995, continues to contribute to dairy science research in the Northeast as

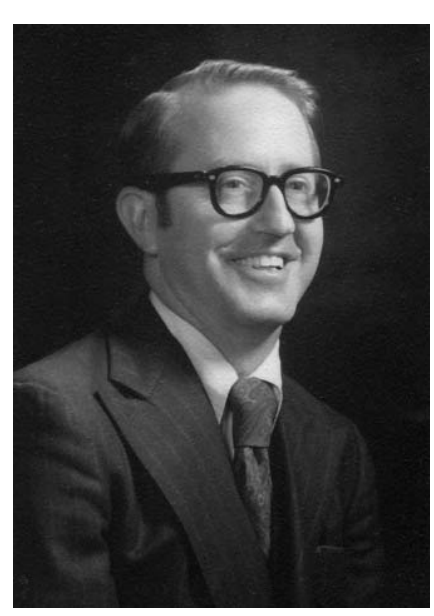

a volunteer at the Animal Improvement Programs Laboratory in Beltsville, Maryland. A graduate of North Carolina State University (BS, agriculture, 1956; $\mathrm{PhD}$, dairy cattle genetics, 1962) and Michigan State University (MS, dairy science, 1958), he began his career with ARS in 1960 as a dairy husbandman with the Animal Research Division in Beltsville. He also served as a biometrician and research geneticist before being appointed in 1972 as chief of the Genetics and Management Laboratory in Beltsville. In 1979, after ARS reorganization, Miller became the research leader of the Milk Secretion and Mastitis Laboratory and remained in that position until his retirement.

In his doctoral research, Miller devised a new genetic experimental design for estimation of nonadditive genetic variation in animals. In his ARS career, he has conducted extensive research on methods to increase the accuracy of genetic evaluations of dairy bulls and developed the theoretical formulation and first implementation of dairy cow evaluations. He conducted a series of studies to quantify milk yield effect from increased milk somatic cell count and bacterial infection as well as a series of studies to determine whether mastitis defense mechanisms are inherited. He led a team that found several genetic markers that were associated with mastitis resistance. His research on mastitis also included an investigation of the effect of intramammary devices on milk yield and a quantification of the role of teat canal keratin in mastitis defense. His most recent research focuses on trends in death losses and abortion frequency of dairy cows. Miller's sustained research productivity is documented in 126 peer-reviewed scientific articles, 19 conference proceedings papers, 17 federal government technical reports, and 139 scientific abstracts.
Miller has participated in the ADSA, the American Association for the Advancement of Science, and the American Genetic Association and served on the Research Committee of the National Mastitis Council. He has been consulted by animal scientists worldwide for research planning, analysis, and data interpretation. He also fostered an active cooperative research program with the Department of Animal Science at the University of Maryland.

\section{Northeast ADSA-ASAS Young Scientist Award - Research}

Heather Dann received a BS degree from Cornell University, an MS degree from the Pennsylvania State University, and a $\mathrm{PhD}$ from the University of Illinois in

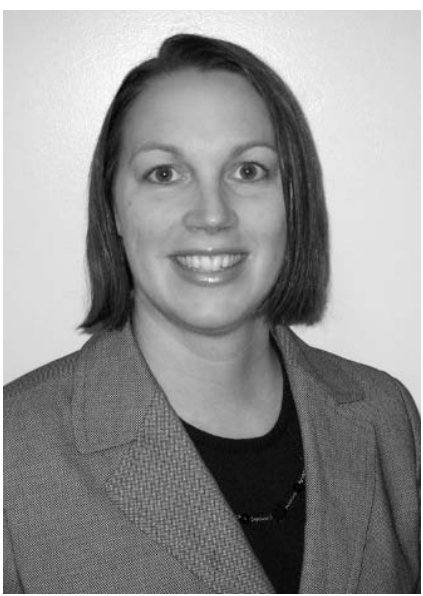
the area of dietary energy restriction during late gestation in dairy cattle. In 2004, Heather joined the William H. Miner Agricultural Research Institute located in Chazy, New York, as a postdoctoral research fellow working in dairy cattle nutrition. In 2005 , she became a fulltime research scientist.

Heather's research focus is controlling the energy content of dry cow diets to optimize periparturient health and productivity.

At the Miner Institute, her primary areas of research have been 1) evaluation of source of carbohydrate in close-up diets on responses in the early lactation period, 2) optimal nutritional strategies for shortened dry periods, and 3) relationships of stocking density during the dry period with health and production following parturition. In addition to these primary areas of focus, Heather has become active in the areas of lignin monomers and forage cell wall digestion as well as rumen modifiers and efficiency of rumen microbial fermentation.

Heather's stature and contributions to the field are demonstrated by grant funding in excess of $\$ 1,000,000$, a lengthy publication record, presentations at numerous industry conferences, and service within ADSA and ASAS. 